\title{
(2) OPEN ACCESS \\ Pancytopenia in a patient treated with fusidic acid and niraparib: a case report
}

\author{
Margaux Damerval @ ${ }^{1}$ ' Fernando Bazan, ${ }^{2}$ Selim Omrani, ${ }^{1}$ Marion Hugues, ${ }^{1}$ \\ Marie-Françoise Roux, ${ }^{1}$ Joséphine Mayer ${ }^{1}$
}

${ }^{1}$ Territoire de Belfort, Hopital Nord Franche-Comte - Site de Belfort, Trévenans, FrancheComté, France

${ }^{2}$ Doubs, Centre Hospitalier Universitaire de Besancon, Besancon, France

\section{Correspondence to} Margaux Damerval, Hopital Nord Franche-Comte - Site de Belfort, 90400 Trévenans, France; margaux.damerval@ orange.fr

Received 29 April 2021 Accepted 8 February 2022

D) Check for updates

(C) European Association of Hospital Pharmacists 2022. Re-use permitted under CC BY-NC. No commercial re-use. Published by BMJ.

\section{To cite: Damerval $\mathrm{M}$, Bazan F, Omrani S, et al. Eur I Hosp Pharm Epub ahead of print: [please include Day Month Year]. doi:10.1136/ \\ ejhpharm-2021-002819}

\section{SUMMARY}

Fusidic acid is an antibiotic used in the treatment of staphylococcal infections. Niraparib is an anticancer drug indicated for the treatment of advanced ovarian cancer. The interaction between these two drugs has not been studied and is not referenced in drug databases. We present the case of a patient with pancytopenia who had been treated with fusidic acid and niraparib. No other treatment was taken by this patient. According to the literature, both substances can cause haematological toxicity. It seems unlikely that this is due to niraparib alone because it had been well tolerated by the patient for over a year before the pancytopenia was diagnosed. It was also perfectly well tolerated when it was reintroduced. We cannot determine whether this pancytopenia is due to fusidic acid alone or to a drug interaction between the two treatments. We therefore recommend caution in patients treated with this combination.

\section{BACKGROUND}

Fusidic acid was first marketed in 1964 in France and is indicated for the treatment of staphylococcaal infections of the skin, bones and joints. The safety profile of fusidic acid is generally good with mainly gastrointestinal side effects. Drug interactions with fusidic acid are poorly documented.

We report a case of pancytopenia which occurred in a patient treated with fusidic acid and niraparib, a PARP enzyme polymerase inhibitor anticancer drug used in the maintenance treatment of platinumsensitive recurrent ovarian cancer.

\section{CASE PRESENTATION}

An 82-year-old woman with high-grade serous adenocarcinoma of the ovary with peritoneal carcinosis was treated with several lines of cancer therapy. She had been receiving treatment with niraparib at a dose of $300 \mathrm{mg}$ once daily since May 2019. She had no other history or comorbidities and did not take any other medication. She had normal liver and kidney functions with a creatinine clearance of $80-90 \mathrm{~mL} / \mathrm{min}$ (CKD-EPI formula) and a normal blood test.

On 8 June 2020 the patient was admitted to the emergency room and then hospitalised for pancytopenia with anaemia $(9.2 \mathrm{~g} / \mathrm{dL})$, leucopenia $(2.29 \mathrm{~g} / \mathrm{L}$ including $0.59 \mathrm{~g} / \mathrm{L}$ neutrophils) and thrombocytopenia $(1 \mathrm{~g} / \mathrm{L})$. Clinically, there was petechial purpura of the lower limbs and bleeding in the mouth.

\section{INVESTIGATIONS}

On 15 May 2020 the patient consulted with her general practitioner with buzzing in her right ear associated with inflammatory signs. The physician decided to prescribe fusidic acid $500 \mathrm{mg}$ twice daily for days.

She was admitted to the emergency room with pancytopenia 14 days after the end of her fusidic acid treatment on 8 June 2020 and a myelogram was performed on 10 June 2020. The report showed very poor granular lineage leading to relative lymphocytosis and blastosis and concluded pancytopenia secondary to probable toxic activity.

The diagnosis was therefore drug intoxication caused by interaction between fusidic acid and niraparib or direct toxicity of one of the two drugs.

\section{TREATMENT}

Niraparib treatment was stopped as soon as the patient was hospitalised in order to normalise the haematological test. She then received two platelet concentrates on day 1 and growth factor treatment (filgrastim (Zarzio), $48 \mathrm{MIU}$ ) from days 2 to 7 . She also received folic acid $5 \mathrm{mg}$, a combination of $\mathrm{B}$ vitamins (Princi B) and cyanocobalamin (vitamin B12) throughout her hospital stay to treat anaemia.

\section{OUTCOME AND FOLLOW-UP}

This treatment normalised the platelet and leucocyte lines and the patient was discharged after 8 days in hospital (haemoglobin $8.3 \mathrm{~g} / \mathrm{dL}$, leucocytes $8.37 \mathrm{~g} / \mathrm{L}$ including $4.39 \mathrm{~g} / \mathrm{L}$ neutrophils and platelets $89 \mathrm{~g} / \mathrm{l})$.

The patient was seen by her oncologist on 1 July 2020. Her blood test showed that only anaemia persisted (haemoglobin $<10 \mathrm{~g} / \mathrm{dL}$ ) and the rest of the blood count had returned to normal. After a therapeutic pause of 3 weeks, treatment with niraparib was then resumed at a sightly reduced dosage of $200 \mathrm{mg}$ once daily.

On 27 July 2020, 1 month after resumption of cancer therapy, the patient was free of anaemia, leucopenia and thrombocytopenia (figure 1). Her cancer treatment was increased to the starting dose of $300 \mathrm{mg}$ daily (figure 2).

\section{DISCUSSION}

The reintroduction of niraparib with maintenance of good haematological tolerance seems to confirm that fusidic acid was responsible for the pancytopenia experienced by this patient. However, we cannot know for certain whether the origin of the pancytopenia was due to the direct toxicity of 
Evolution of test results

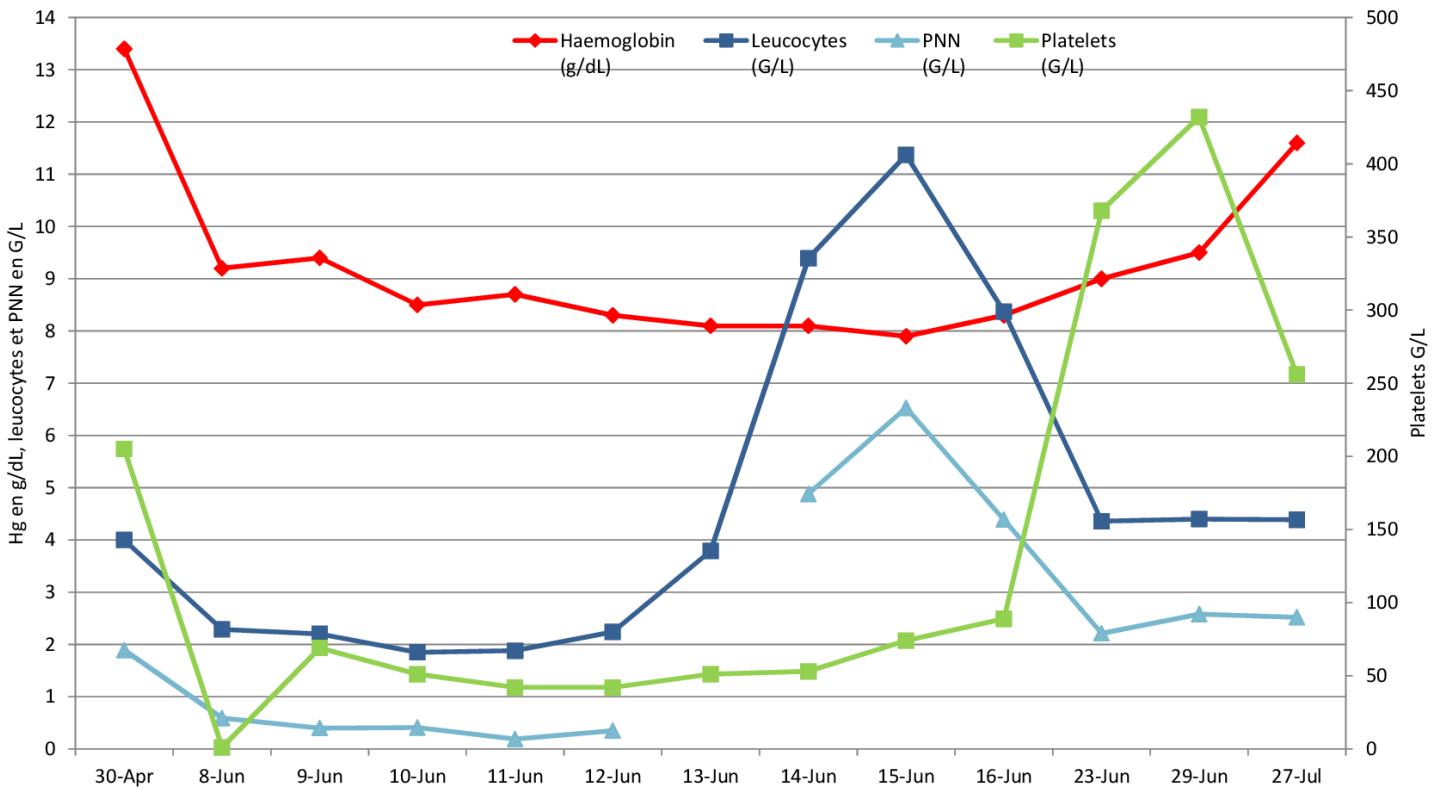

Figure 1 Evolution of blood count.

fusidic acid or to an interaction between the two drugs or to another unknown underlying cause.

Haematological toxicity (agranulocytosis, thrombocytopenia, neutropenia, anaemia) has been reported with fusidic acid treatment. However, the frequency is less than $1 \%$ and the cases reported in the literature do not demonstrate with certainty that these events are related to fusidic acid alone. ${ }^{1}$ In addition, the haematological events reported were observed in particular in patients treated with fusidic acid for more than 15 days. The damage occurred within 4 days to 6 weeks after the start of treatment, with a rapid normalisation of the haematological test when fusidic acid was stopped. ${ }^{2}$ Our patient was treated for 10 days and pancytopenia was detected approximately 3 weeks after the start of treatment. Thus, direct toxicity of fusidic acid appears to be possible.

Niraparib is also a drug that can cause haematological damage. Unlike fusidic acid, the probability is very high (60\% thrombocytopenia, 50\% anaemia, 30\% neutropenia of any grade), but cases of pancytopenia represent less than $1 \%$. These haematological adverse events usually appear at the beginning of treatment and their incidence decreases over time. ${ }^{34}$ At the time of this event our patient had been treated with niraparib for more than a year with excellent haematological tolerability. With prolonged use, cases of myelodysplasia have been described between 6 months and 5 years after initiation of niraparib, ${ }^{5}$ which may explain the patient's disturbed biological status. The myelogram performed during hospitalisation showed a poor marrow in favour of pancytopenia secondary to probable toxic activity. The myelodysplastic syndrome is therefore eliminated and we can deduce that niraparib alone is not responsible for this event.

The other hypothesis is a drug interaction between fusidic acid and niraparib. These two medications both have relatively high binding to plasma proteins, in particular to albumin $(97 \%$ for fusidic acid and 83\% for niraparib). As shown by BousquetMélou and Toutain, the hypothesis of an interaction linked to competitive plasma protein binding is unlikely because these two substances do not have either a narrow therapeutic index or high clearance elimination. ${ }^{6}$ The interaction between the

Treatment plan

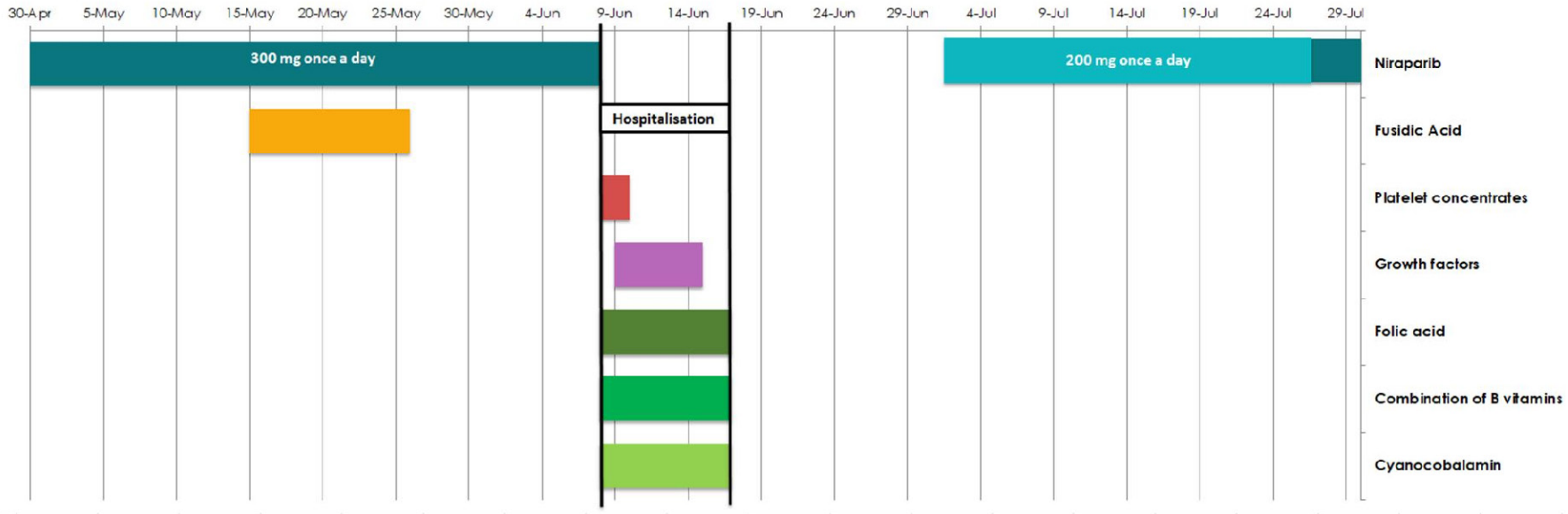

Figure 2 Treatment plan. 
two drugs may also occur at the metabolic level. Indeed, fusidic acid is an inhibitor of cytochromes, particularly CYP3A4. In the study by Marsot et al published in $2017,{ }^{7}$ the co-administration of fusidic acid and rifampicin, metabolised by deacetylation and hydrolysis, resulted in supratherapeutic plasma concentrations of rifampicin. Similarly, the case study published by Khaliq et al in $2000^{8}$ showed an increase in antiretroviral concentrations by inhibition of CYP3A4 when co-administered with fusidic acid. On the other hand, niraparib is metabolised in a minority manner by oxidation by cytochromes including CYP3A $4 / 5 .^{9}$ Although inhibition of CYP3A4 in the liver is not expected, the potential for inhibition of CYP3A4 in the gut has not been established at significant concentrations of niraparib. ${ }^{3}$ Thus, a metabolic interaction between fusidic acid and niraparib cannot be excluded.

\section{Learning points}

Fusidic acid and niraparib are known to be responsible for haematological toxicity. Since the patient had been on niraparib for more than a year with very good tolerance, it seems unlikely that the pancytopenia was due to niraparib alone. Even though the mechanism of the haematological toxicity of fusidic acid is unknown, fusidic acid alone could be responsible for the pancytopenia.

- We cannot rule out a drug interaction between fusidic acid and niraparib due to the lack of experience with niraparib use and the lack of literature on fusidic acid. We therefore recommend avoiding the combination of these two drugs, especially since oral fusidic acid is no longer part of first-line antibiotic therapy.

- This case highlights the importance of information shared between the general practitioner, oncologist and the pharmacist so that analysis of the risk of an interaction is systematically carried out when a new drug is prescribed to a patient already receiving oral cancer treatment.
Contributors Guarantors: MD and JM.

Funding The authors have not declared a specific grant for this research from any funding agency in the public, commercial or not-for-profit sectors.

Competing interests None declared.

Patient consent for publication Obtained.

Ethics approval Not applicable.

Provenance and peer review Not commissioned; externally peer reviewed.

Data availability statement All data relevant to the study are included in the article.

Open access This is an open access article distributed in accordance with the Creative Commons Attribution Non Commercial (CC BY-NC 4.0) license, which permits others to distribute, remix, adapt, build upon this work non-commercially, and license their derivative works on different terms, provided the original work is properly cited, an indication of whether changes were made, and the use is noncommercial. See: http://creativecommons.org/licenses/by-nc/4.0/.

\section{ORCID iD}

Margaux Damerval http://orcid.org/0000-0001-9997-3395

\section{REFERENCES}

1 Kraus CN, Burnstead BW. The safety record of fusidic acid in non-US markets: a focus on skin infections. Clin Infect Dis 2011;52 Suppl 7:S527-37.

2 Résumé des caractéristiques du produit - Acide fusidique. Available: http://agence-prd. ansm.sante.fr/php/ecodex/rcp/R0207358.htm

3 Résumé des caractéristiques du produit - Niraparib. Available: https://ec.europa.eu/ health/documents/community-register/2017/20171116139116/anx_139116_fr.pdf

4 Moore KN, Mirza MR, Matulonis UA. The poly (ADP ribose) polymerase inhibitor niraparib: management of toxicities. Gynecol Oncol 2018;149:214-20.

5 Mirza MR, Monk BJ, Herrstedt J, et al. Niraparib maintenance therapy in platinumsensitive, recurrent ovarian cancer. N Engl J Med 2016;375:2154-64.

6 Bousquet-Mélou A, Toutain PL. Les interactions impliquant les protéines plasmatiques ne sont plus ce qu'elles étaient. La Lettre du Pharmacologue 2012;26:44-50.

7 Marsot A, Ménard A, Dupouey J, et al. Population pharmacokinetics of rifampicin in adult patients with osteoarticular infections: interaction with fusidic acid. $\mathrm{Br} J \mathrm{Clin}$ Pharmacol 2017:83:1039-47.

8 Khaliq Y, Gallicano K, Leger R, et al. A drug interaction between fusidic acid and a combination of ritonavir and saquinavir. Br J Clin Pharmacol 2000;50:83-4.

9 European Medicines Agency. Public assessment report: Zeluja, 2017. Available: https:// www.ema.europa.eu/en/documents/assessment-report/zejula-epar-public-assessmentreport_en.pdf 